\title{
LA NOCIÓN DE PLURALISMO EN EMMANUEL LÉVINAS*
}

\section{THE CONCEPT OF PLURALISM IN EMMANUEL LÉVINAS..}

\author{
Mateo Navia Hoyos**
}

\section{Resumen}

En el siguiente artículo, el planteamiento filosófico-metafísico de Lévinas es abordado desde su formulación de la subjetividad como Yo y Mismo hasta la aparición del Otro, para plantear que la idea de lo infinito anuncia la orientación del Mismo hacia el Otro. De este modo, la noción de pluralismo en Lévinas queda enmarcada en dos condiciones fundamentales: la subjetividad separada fundada en la idea de lo infinito, y su orientación hacia el Otro que proviene de la idea de lo infinito en el Otro.

\section{Palabras clave}

Subjetividad, pluralismo, Mismo, Otro, Idea de lo Infinito, separación, excedencia.

\begin{abstract}
In the following article, the philosophical-metaphysical formulation of subjectivity in Lévinas is showed from its Me and The Same to the emergence of The Other. The Idea of Infinite announces the orientation of The Same towards The Other. Therefore, the notion of pluralism in Lévinas is framed in terms of two fundamental conditions: the isolated subjectivity grounded in the Idea of Infinite and its orientation towards The Other, that comes from the Idea of Infinite in The Other.
\end{abstract}

\section{Key-words}

Subjectivity, pluralism, the same, the Other, Idea of Infinite, isolation, exceeding.

Dos versiones preliminares de este trabajo se presentaron en el III Congreso Iberoamericano de Filosofía. Pluralismo (Medellín 1 al 5 de julio de 2008), y en el II Encuentro Iberoamericano de Estudiantes de Filosofía (Bogotá 30 de marzo al 4 de abril de 2009).

** Filósofo de la Universidad de Antioquia. Magíster en Historia (C) Universidad Nacional de Colombia, Sede Medellín. Profesor del Departamento de Humanidades de la Universidad EAFIT (Colombia). Correo electrónico: ultimaletra@gmail.com 
En las exposiciones sobre Emmanuel Lévinas es usual se comience por instaurar la anterioridad del Otro respecto al Yo. En ellas, la anterioridad filosófica del Otro logra alcances, incluso biológicos, que no desorientan la fidelidad a la letra de Lévinas. Contraria a esta tendencia, la siguiente exposición se desplegará desde la interpretación según la cual, en el marco de la relevancia y el posicionamiento del Otro, Lévinas defiende una subjetividad fundada en la idea de lo infinito. Por tanto, este artículo no comenzará por establecer la anterioridad del Otro, sino que, rastreando algunos contenidos de la subjetividad levinasiana, se topará ante el Otro, no como límite, sino enmarcado en una distancia infinita en la cual aparece. De este modo, se abordará la formulación de la noción de pluralismo en Totalidad e infinito. Ensayo sobre la exterioridad (1961), para, con los elementos que descubren la subjetividad levinasiana, presentar las condiciones y cimientos que posibilitan la noción misma de pluralismo.

El procedimiento será el siguiente: en un primer numeral, se detallarán algunos elementos de la subjetividad levinasiana que evidencian al Yo como ser separado, único y particular en el punto de partida; en un segundo numeral, se reconstituirá, de manera breve, la fundamentación de la noción de pluralismo desde la separación de la subjetividad respecto al ser, para enmarcar la distancia en la cual el Otro aparece en su excedencia; y finalmente, en un tercer numeral, se retomará la separación y la excedencia del Otro en la idea de lo infinito, para establecer las condiciones que aseguran la instauración de la noción de pluralismo.

Estimar lo relevante de la separación radical de la subjetividad y la excedencia del Otro, permite vislumbrar el establecimiento de una subjetividad separada ante la instauración de la anterioridad del rostro del Otro, asegurándose, de este modo, la tesis vital planteada por Lévinas en Totalidad e infinito, a saber, la defensa de una subjetividad fundada en la idea de lo infinito (Lévinas, 2000, p. 52). Pero ¿qué quiere decir que la subjetividad esté fundada en la idea de lo infinito?, y sobre todo, ¿qué importancia deviene de ello para la fundamentación de la noción de pluralismo? Estos interrogantes sólo podrán responderse en el último numeral de esta interpretación.

\section{Elementos de la subjetividad}

Dice Lévinas:

La alteridad, la heterogenidad radical de lo Otro, sólo es posible si lo Otro es otro con relación a un término cuya esencia es permanecer en el punto de partida, servir de entrada a la relación, ser el Mismo no relativamente, sino absolutamente. Un término sólo puede permanecer absolutamente en el punto de partida de la relación en tanto que Yo (Lévinas, 2000, p. 60).

En primera instancia, parece establecerse una ligera distinción entre el Yo y el Mismo, siendo el último una radicalización no relativa sino absoluta del Yo. Y este último, aunque marca el punto de partida no sirve de entrada a la relación. Más adelante, Lévinas indica esta diferenciación de un modo más preciso, "La identificación del Mismo en el Yo no se produce como la monótona tautología: $<$ Yo es Yo $>$. Es necesario captarla sin reflexionar sobre la abstracta representación de sí por sí. Es necesario partir de la relación concreta entre un yo y un mundo" (Lévinas, 2000, p. 61). El proceso de identificación aludido por Lévinas apunta a un momento más explícito, menos abstracto; pero ¿sería necesario reconstruir todos los análisis sobre la estancia del Yo en el mundo, en el cual ha de conformarse como Mismo, para captar este salto del Yo al Mismo? Tal vez (Sucasas, 1998, pp. 38- 
43). Sin embargo, puede decirse, omitiendo esa reconstrucción, que la constitución del Mismo $^{1}$ aparece cuando el Yo ha acudido al llamado del Otro y lo Otro, al atender la invocación de la exterioridad. El Mismo, en esa perspectiva, posterior al Yo, resulta de la relación metafísica que establece con el Otro. Y para que el Yo haya podido descubrirse o producirse -término que Lévinas prefiereMismo, ha tenido que "reconocer" al otro como Otro en su Altura.

Una aclaración preliminar importante. Cuando se habla en Lévinas de relación metafísica, se alude al encuentro entre el Mismo y el Otro $^{2}$. El Mismo (Moi) debe entenderse como la reiteración del Yo $(\mathrm{Je})$, como la radicalización de su egoísmo. El Mismo con su egoísmo, en su gozo y plenitud, está separado radicalmente del Otro. El Otro es irreductible al Mismo, no simplemente porque no pueda ser conocido, sino porque de su revelación, de su manifestación, depende la aparición del Yo y, por tanto, del Mismo.

En este punto es imprescindible desarrollar dos aclaraciones fundamentales que pueden

1 Aquí debemos recordar la "definición" del Mismo. El Mismo como lo "concreto" del egoísmo indica el tránsito de un Yo egoísta que subordina al Otro, a un Mismo -también egoísta- pero que dé su atención al Otro, se descubre separado.

2 Alberto Sucasas se refiere a esto en términos de forma matricial de lo interhumano: "el discurso filosófico de Lévinas representa un esfuerzo sostenido por proteger al pensamiento de la seducción de la Unidad, hegemónica en una tradición filosófica dominada por la Seinsfrage. No a la ontología, sino a la ética, corresponde la dignidad de ser la filosofía primera. Y el sentido primordial de la ética es la dualidad Mismo-Otro, forma matricial de lo interhumano. Denunciando la pulsión egoísta subyacente a la filosofía de la conciencia, Lévinas reivindica un humanismo que privilegie la alteridad del prójimo, un humanismo del otro hombre" (Sucasas, 1998, p. 10). presentarse de modo simultáneo. De un lado, las indicaciones sobre el "reconocimiento" del otro como Otro; y de otro lado, la asimetría que se devela de la Altura del Otro. Dice Lévinas: "Y si el otro puede investir mi libertad por sí misma arbitraria, es porque yo mismo puedo sentirme, a fin de cuentas, como el Otro del Otro" (Lévinas, 2000, pp. 106-107). La oposición entre el Mismo y el Otro no se plantea en términos de dos yo que se enfrentan o relacionan. La distinción, la diferenciación, es profundamente radical ${ }^{3}$. El Mismo es Mismo, el Otro es Otro, y sólo sentirme delata la ligazón que los une, la relación en la cual se encuentran. El establecimiento no se da entonces en términos de reciprocidad, la asimetría está en la base y constituye el fundamento mismo de la relación metafísica. Dice Lévinas:

Una separación del Yo que no es la recíproca de la trascendencia del Otro con respecto a mí, no es una eventualidad en la que sólo piensen los buscadores de la quinta esencia. Se impone a la meditación en nombre de una experiencia moral concreta -lo que exijo a mí mismo no es comparable a lo que tengo derecho de exigir del Otro-. Esta experiencia moral, tan trivial, indica una asimetría metafísica: la imposibilidad radical de verse desde fuera y de hablar en el mismo sentido de sí y de los otros; en consecuencia también la imposibilidad de la totalización (Lévinas, 2000, p. 77; énfasis nuestro).

3 En este punto del argumento, la oposición de Lévinas al argumento de la Quinta meditación de las Meditaciones Cartesianas de Edmund Husserl, puede resultar relevante. Al respecto del tránsito Husserl-Lévinas: Hoyos, 1999, pp. 127-145. 
El planteamiento levinasiano se $\operatorname{articula}^{4}$ a partir de la "trivialidad" apuntada, inscribiendo la asimetría entre el Mismo y el Otro. La totalidad es rebasada, y la posibilidad de hablar de sí y de los otros se clausura mediante una profunda captación de lo inapresable de sí y de los otros. De este modo, el término Altura del Otro adquiere toda su fuerza y significación. Sin embargo, no puede incurrirse en el error de llegar a pensar que el Mismo se encuentra "abajo". Lo reversible ha sido extirpado y anulado, en tanto la relación es irreversible. El otro es Otro porque el Mismo puede sentirse como el Otro del Otro. Modificando lo anterior, el Otro es Altura y el Mismo dirige hacia él sus ojos. Pero el Otro es también el huérfano, la viuda, el enfermo, el extranjero; puede estar Abajo, y el Mismo puede sentirse como el Otro del Otro ${ }^{5}$.

De este modo, mediante la dilucidación de la relación hemos ido ingresando de un modo natural en las articulaciones que se dan en el Mismo. Para puntualizar lo que Lévinas indica para la ipseidad, esta cita resulta reveladora: "La relación del Mismo y del Otro - o metafísica - [...] en el que el

4 Otras articulaciones que Lévinas incluye son las siguientes: 1. El Yo es identificación de sí, en tanto constituye al Mismo en el cual se identifica, incluso mediante aquellas relaciones que competen a su propia alteridad. Es decir, el Yo puede para sí ser otro y esta penetración en sus profundidades no lo extravían ni desorientan. El Yo para ser Yo o Mismo, logra en medio de otros alternos que pone delante, su propia identificación. 2. "La idea de lo Infinito supone la separación del Mismo con relación al Otro" (Lévinas, 2000, p. 76).

5 Con esta transformación en los términos para plantear la relación que Lévinas introduce, radicaliza la no posibilidad de que la "y" entre el Mismo y el Otro constituya una totalidad. "Pero yo, que no pertenezco a un concepto común con el extranjero, soy como él, sin género. Somos el Mismo y el Otro. La conjunción $y$ no indica aquí ni adición ni poder de un término sobre otro" (Lévinas, 2000, p. 63).
Mismo, resumido en su ipseidad de $<$ yo $>$ -de ente particular único y autóctono- sale de sí" (Lévinas, 2000, p. 63). El tratamiento del Mismo como parte del Yo, y éste como ente particular único y autóctono homologa la ipseidad en una transposición sinonímica que le presta su sentido. La expresión latina ipse es radicalizada como auto-referencia, es decir, lo que del Mismo va al Mismo; esto es, nuevamente, lo concreto del egoísmo ${ }^{6}$.

En el lugar de la noción de interioridad, el sujeto como Mismo logra entonces, además de su aseguramiento idéntico, un orden en el cual todo queda aún pendiente, pues, como aplazamiento, reserva y licencia, se distancia de la totalidad en tanto accede a una nueva comprensión del tiempo histórico. "Para que haya ser separado, para que la totalización de la historia no sea el último designio del ser, es necesario que la muerte que, para los sobrevivientes es fin, no sea solamente este fin; es necesario que haya en el morir otra dirección que la que lleva al fin como a un punto de impacto en la duración de los sobrevivientes" (Lévinas, 2000, p. 79). La memoria deja de ser aquella de los vencedores y los sobrevivientes, posesionándose en la posterioridad que puede lograr asumir el pasado como dominio y pasividad. Y esta nueva conceptualización sobre la memoria que Lévinas recupera, invierte el tiempo histórico, pues ya no funda el motivo por el cual la voluntad consiente su pertenencia a una continuidad histórica, sino que

6 Según nuestra propia lectura, la ipseidad parece tener una cercanía bastante relevante con el psiquismo. Conscientes del estrechamiento de esta relación, entendemos que la ipseidad llega a parecerse tanto al psiquismo que la ligazón con el alma logra asegurarse, y, en esta perspectiva, la tesis inicial de Lévinas sobre que Totalidad e Infinito sea un libro que persigue una defensa radical de la subjetividad adquiere un sentido mayor. "El alma -la dimensión de lo psíquico-, realización de la separación, es radicalmente atea" (Lévinas, 2000, p. 82). 
ha de sentirse como la arista de un nuevo comienzo. Lévinas ha aludido al momento de las relaciones del Yo y la voluntad como las paradojas en que gravita el psiquismo. Es decir, que la historia universal marque el inicio para la realidad de la subjetividad, o que la interioridad, resistiéndose desde su soledad, tome su nacimiento y su muerte, sin pedir prestada su significación de la historia (Lévinas, 2000, pp. 78-79).

De este modo, arribamos al punto en el cual Lévinas justifica la existencia del Yo o Mismo, mediante el psiquismo. La defensa se produce al tiempo que se establecen las relaciones con la idea de infinito y la totalidad. Pues, el psiquismo, en tanto no es asumido como reflejo del ser -tal como algunos filósofos de la tradición han pretendido-, sino como modalidad del ser, se resiste en defensa de su vida interior, a esta totalización. El psiquismo $\mathrm{y}$, por tanto, el Yo se resiste a ser totalizado en el ser, afirmando, de este modo, su separación radical como Mismo7.

Lévinas realiza la justificación apelando a la tercera meditación de las Meditaciones $\mathrm{Me}$ tafísicas de Descartes, en la cual la existencia del cogito se justifica en la posterioridad de la anterioridad. Es decir, el yo sabe de su existencia ex nihilo como si fuese posterior. El acontecimiento positivo por medio del cual el Yo se sabe un yo existente, es sólo posible en tanto el yo piensa su causa al conocerla por su efecto - la existencia misma de la cual ahora dispone-, como si fuese posterior al efecto. Y esta participación del "como si"

7 "El papel original del psiquismo no consiste, en efecto, en reflejar solamente el ser. Es ya una modalidad del ser, la resistencia a la totalidad. El pensamiento o el psiquismo abre la dimensión que requiere esta modalidad. La dimensión del psiquismo se abre por el empuje de la resistencia que opone un ser a su totalización, es el hecho de la separación radical. El cogito, hemos dicho, testimonia la separación" (Lévinas, 2000, p. 77).
Lévinas no la asume como una ilusión sino como el acontecimiento positivo mismo. Más aún, ha dicho Lévinas, para que todo ello acontezca "el fenómeno <inverosímil> de la memoria o el pensamiento, debe interpretarse precisamente como revolución en el ser" (Lévinas, 2000, p. 78). La revolución se efectúa entonces como enfrentamiento y pugna contra la totalización en la cual el ser se siente seguro y, por ende, el hecho de que un ser separado provenga de la nada se justifica en tanto la apelación a la idea de lo infinito afirma un nuevo reconocimiento de la situación ${ }^{8}$.

Sin embargo, esta apelación a la idea de lo infinito denota al ser creado como ateo. "Se puede llamar ateísmo a esta separación tan completa que el ser separado se mantiene sólo en la existencia sin participar en el Ser del que está separado, capaz eventualmente de adherirse a él por la creencia. La ruptura con la participación está implicada en esta capacidad" (Lévinas, 2000, p. 82). Lévinas no está rechazando completamente la posible adhesión al ser como totalidad; un hombre puede matricularse en la totalidad si lo desea. No obstante, el esfuerzo consiste en recuperar el momento de la separación, de la distancia que se produce en el Yo como Mismo, en el modo de una instancia anterior. Por esto, dirá Lévinas, “[p]or ateísmo, comprendemos así

8 "La creación ex nihilo rompe el sistema, pone un ser fuera de todo sistema, es decir, allí donde es posible la libertad. La creación deja a la criatura un vestigio de dependencia, pero de una dependencia sin paralelo: el ser dependiente saca de esta dependencia excepcional, de esta relación, su independencia misma, su exterioridad al sistema. Lo esencial de la existencia creada no consiste en el carácter limitado de su ser y la estructura concreta de la criatura no se deduce de esta finitud. Lo esencial de la existencia creada consiste en su separación frente a lo infinito. Esta separación no es simplemente negación. Al realizarse como psiquismo, se abre precisamente a la idea de lo Infinito" (Lévinas, 2000, p. 127). 
una posición anterior a la negación o afirmación de lo divino, la ruptura de la participación a partir de la cual el yo se implanta como él mismo y como yo" (Lévinas, 2000, p. 82).

Así, arribamos al punto en el que, consideramos, se anuda el corpus levinasiano, mediante el entrelazamiento de las intenciones interiores y el pluralismo de la sociedad. El secreto consiste en asumir al Mismo, a la subjetividad, como aquella que irrumpe en el tiempo histórico. Cito in extenso:

Lo real no debe estar determinado solamente en su objetividad histórica, sino también a partir del secreto que interrumpe la continuidad del tiempo histórico, a partir de intenciones interiores. El pluralismo de la sociedad sólo es posible a partir de este secreto. Él testimonia este secreto (énfasis nuestro). Sabemos desde siempre que es imposible hacerse una idea de la totalidad humana, porque los hombres tienen una vida interior cerrada a aquel que, sin embargo, aprehende los movimientos globales de los grupos humanos. El acceso a la realidad social a partir de la separación del Yo, no es devorado en la $<$ historia universal $>$ en la que sólo aparecen totalidades. La experiencia del Otro a partir de un Yo separado sigue siendo una fuente de sentido para la comprehensión de las totalidades, como la percepción concreta sigue siendo determinante para la significación de los universos científicos. Cronos cree tragarse un dios y sólo traga una piedra (Lévinas, 2000, p. 81).

La recapitulación sobre el sentido que deba otorgársele a la alteridad toma toda su gravedad y seriedad. ¿Es la reducción de la alteridad del Otro, el camino a seguir? La continuación de esta ilusión nos ha conducido a horrores inhumanos que la historia atestigua. Por ende, los pasos que han de efectuarse tienen como horizonte la posibilidad de que se implante una relación con la alteridad a partir de la separación que ha sido instaurada. Separación con la cual las intenciones interiores del Yo pueden rebelarse ante la totalidad de una historia universal. Capacidad de no ser devorado que asegura el secreto que una noción de pluralismo debe salvaguardar. De esta manera, mediante la configuración de un Yo separado, único y particular -esto es, como más arriba lo veíamos, ateo-, se establecen las condiciones para que una alteridad "se produzca en el ser" (Lévinas, 2000, p. 63), y para que el pluralismo cumpla con su cometido central: albergar en su seno una multiplicidad de seres únicos, particulares, separados e incomparables.

\section{La noción de pluralismo}

En el numeral anterior hemos logrado posicionar al Mismo, a la subjetividad, en el punto de partida de la relación metafísica, y hemos detenido la exposición en el momento en que el Otro hacía su aparición, sin dejar de mencionar la inclusión de la subjetividad única y particular en la estructura de una posible noción de pluralismo. En este numeral expondremos y explicaremos la fundamentación del pluralismo en la perspectiva de la instauración del Otro. Aquí se espera insistir, además, en la separación de la subjetividad frente al ser, y en la distancia en la cual se enmarca el Otro.

Respecto al pluralismo, dice Lévinas: "Para que una multiplicidad pueda mantenerse, es necesario que se produzca en ella la subjetividad de modo que no pueda ser congruente con el ser en el que se produce" (Lévinas, 2000, pp. 233-234). Es decir, la subjetividad no está ligada, según Lévinas, al ser. La subjetividad es incongruente con él; y esta asunción 
defiende y protege la primacía del sujeto en el ser permitiéndole un posicionamiento tal que no destruye su exterioridad misma. Con otras palabras, el movimiento del ser que va hacia la subjetividad no puede estabilizarse en un conocimiento que resultaría de sus reflexiones, pues nuevamente se estaría ocasionando una integración. En esta perspectiva, se implica, según Lévinas, la imposibilidad de la reflexión total, en tanto la subjetividad no puede colmar ni englobar el ser en el cual se desliza. Pero ¿qué se logra mediante el hallazgo de la imposibilidad de la reflexión total? La refutación de los planteamientos que arguyen la finitud del sujeto cognoscente como negativa. Pues, la dirección que toma esta nueva comprensión de la relación con el conocimiento y el ser, acepta la "excedencia de la relación social en la que la subjetividad permanece de cara a..., en la lealtad de este recibimiento, y no se mide por la verdad" (Lévinas, 2000, p. 234). No obstante, Lévinas demarca de manera cuidadosa esta imposibilidad de la reflexión total.

El discurso mismo con que lo anuncio y cuya pretensión de verdad - que postula una reflexión total- refuta el carácter insuperable de la relación del cara-a-cara, lo confirma sin embargo por el hecho de enunciar esta verdad, de decirla al otro. La multiplicidad supone pues una objetividad planteada en la imposibilidad de una reflexión total, en la imposibilidad de confundir en un todo el yo y el no-yo. Esta imposibilidad no es negativa (eso sería plantearla todavía en relación al ideal de la verdad contemplada). Esta imposibilidad se debe a la excedencia de la epifanía del Otro que me domina desde su altura (Lévinas, 2000, p. 234, énfasis mío).
Es decir, cuando Lévinas propone una objetividad planteada como imposibilidad de una reflexión total, porque en ella se establece la condición para una multiplicidad que no confunde en un todo el yo y el no-yo, enuncia su verdad desde la excedencia de la epifanía del Otro. La absoluta separación del Otro indica y porta la excedencia que le llega a la subjetividad, conllevando, en este acercamiento, la verdad de la imposibilidad del acercamiento o el conocimiento mismo. De ahí su condición positiva, pues no se hace alusión a un ideal determinado, sino a la excedencia del Otro.

De este modo, puede comprenderse que Lévinas fundamente el pluralismo, la multiplicidad, la relación social -todos sinónimos- mediante la excedencia que enmarca la imposibilidad de una reflexión o conocimiento total. Los términos de la relación permanecen absolutamente separados, aunque no necesariamente aislados en la imposibilidad de la relación. Y es justamente porque, según Lévinas, la relación social es el último acontecimiento que puede producirse en el ser, que el encuentro entre el Mismo y el Otro anuncia la relación metafísica desde la cual se funda el pluralismo. Así, llegamos a un punto subrayable en el planteamiento filosófico levinasiano, la integración de la relación social como encuentro entre el Mismo y el Otro y la fundamentación del pluralismo. Recuperación de la excedencia del Otro que asegura la verdad de un discurso que se dice a otro. Con otras palabras, en la lealtad del recibimiento de la excedencia del Otro se instaura, no la posibilidad del conocimiento sino la imposibilidad del mismo, es decir, el reconocimiento de la distancia en la cual el Mismo y el Otro no se confunden, permanecen separados y, sin embargo, en relación. Distancia que sólo puede ser medida en términos del Deseo que surge de la idea de lo infinito del Otro. 


\section{La idea de lo infinito, condición de la fundamentación de la noción de pluralismo}

Con los dos apartados anteriores hemos traslucido varias consideraciones importantes: la separación, la excedencia y la idea de lo infinito; las cuales, puede decirse, constituyen la base, las condiciones que posibilitan la fundamentación de la noción de pluralismo. Más que devolvernos sobre lo ya recorrido, a continuación ahondaremos en lo referente a la idea de lo infinito enmarcada por el Otro, para, de ese modo, balancear la presentación sobre la subjetividad separada. Y este viraje es relevante si se advierte que "[1]a idea de lo Infinito supone la separación del Mismo con relación al Otro" (Lévinas, 2000, p. 76), y además, que "la idea de lo Infinito es la trascendencia misma, el desbordamiento de una idea adecuada" (Lévinas, 2000, p. 103), porque con la idea de lo infinito se anuncia la orientación del Mismo hacia el Otro desde su separación. Es decir, la separación del Mismo con relación al Otro, está en el origen de la constitución de la relación metafísica entre los términos, pero la idea de lo infinito, al señalar la trascendencia en la cual se inscribe el Otro, trasluce una distancia que no puede ser rebasada por el Mismo, pero en la cual se despliega su movimiento.

En esta perspectiva, y al decir Lévinas que "[n]o es la suficiencia del yo la que impide la totalidad, sino lo Infinito del Otro" (Lévinas, 2000, p. 103), la idea de lo infinito no sólo rebasa las barreras de la totalidad, vincula la noción de pluralismo a una nueva especificidad sobre los límites. El pluralismo en Lévinas, en el contexto de la idea de lo infinito, no logra orientar el Mismo hacia una totalidad, antes bien, afianza en el Mismo su separación de lo infinito del Otro, y profundiza una distancia, un alejamiento que no permite integración posible, dígase género humano o síntesis impersonal. Más aún, la idea de lo infinito como la trascendencia misma que se produce en el Otro, le señala al Mismo separado, una idea que lo desborda, que le es inadecuada.

Sobre esta relación entre la idea de lo infinito y el Mismo, dice Lévinas:

Importa subrayar que la trascendencia de lo Infinito con respecto al Yo que está separado de ella y que lo piensa, mide, si se puede decir, su infinitud misma. La distancia que separa ideatum e idea constituye aquí el contenido del ideatum mismo. Lo infinito es lo propio en un ser trascendente en tanto que trascendente, lo infinito es lo absolutamente otro. Lo trascendente es el único ideatum del cual no puede haber más que una idea en nosotros; está infinitamente alejado de su idea -es decir exterior- porque es infinito (Lévinas, 2000, p. 73).

Lo trascendente señala la instancia en la cual el Yo o Mismo piensa y mide la infinitud de lo infinito que se le aparece, sin lograr englobar, apresar o totalizar al Otro como trascendente. A lo infinito del Otro sólo puede accederse en su trato como trascendente. Lo infinito, trascendente o extraño, pensados no como límites sino como aquello que precisamente desborda los límites, solicita del pensamiento otras categorías, las cuales Lévinas formula como pensar mejor o más que pensar. "La infinición se produce en el hecho inverosímil en el que un ser separado, fijado en su identidad, el Mismo, el Yo contiene, sin embargo, en sí lo que no puede contener, ni recibir por la sola virtud de su identidad. La subjetividad realiza estas exigencias imposibles: el hecho asombroso de contener más de lo que es posible contener" (Lévinas, 2000, p. 52, énfasis mío). 
A este respecto, Lévinas es enfático al reconocer en el hecho de que la subjetividad pueda contener más de lo que es capaz, su acercamiento a lo infinito en términos de lo deseable: "Lo infinito no es <objeto> de un conocimiento -lo que lo reduciría a la medida de la mirada que contempla- si no lo deseable, lo que suscita el Deseo, es decir, lo que es abordable por un pensamiento que en todo momento piensa más de lo que piensa" (Lévinas, 2000, p. 85). De este modo, el Deseo, suscitado por la idea de lo infinito en el Otro, vincula una subjetividad que puede pensar más de lo que piensa, en una orientación que lo conduce al Otro. Así, la idea de lo infinito como modo de ser de lo infinito, se revela como desproporción y desmesura para sugerir un pensamiento que desborda y rebasa los contenidos mismos del pensamiento teórico o del pensamiento fenomenológico de la intencionalidad, describiéndose mediante el Deseo. Lográndose con ello, lo sucintamente recopilado por Patricio Peñalver: "La diferencia entre la idea de infinito y las ideas abarcables por la subjetividad da el modelo de la diferencia entre la relación puramente teórica y el pensamiento metafísico" (Peñalver, 2001, p. 68).

En esta perspectiva, la articulación de la separación y la idea de lo infinito en el Otro en la relación metafísica entre el Mismo y el Otro, -la cual constituye el pilar del pensamiento metafísico levinasiano-, ofrecen las directrices para una comprensión de la noción de pluralismo. La Ética como filosofía primera se inscribe como la defensa de una subjetividad que depende, para su aparición misma, del Otro, antes del arribo mismo del ser. Y, con ello, la ética levinasiana lejos del carácter teórico, científico o incluso normativo, se despliega mediante cuidadosos análisis descriptivos desde una primera demarcación: el encuentro ético entre dos términos radicalmente separados: el Mismo y el Otro, donde la orientación está demarcada por la idea de lo infinito, impidiéndose con ella que se constituya una totalidad, para permitir generar y promover que se constituya una pluralidad de seres separados, pero en relación.

La fundamentación del pluralismo aportada por Lévinas está supeditada a dos condiciones imprescindibles: la subjetividad separada fundada en la idea de lo infinito, y su orientación hacia el Otro a partir de la idea de lo infinito en el Otro. La separación asegura un Mismo radicalmente egoísta, satisfecho y pleno en su egoísmo, pero ante el arribo de la desmesura, de la excedencia, de la idea de lo infinito en el Otro, se genera en él una orientación que se trasluce en el recibimiento de la idea de lo infinito. Con estas características, la descripción de la relación metafísica entre el Mismo y el Otro exceptúa, al menos en este abordaje, la participación de un tercero en la relación, el cual transportaría los términos a un plano común. En cambio, la relación metafísica entre el Mismo y el Otro, al contar con la noción de pluralismo, que desde este ámbito metafísico no puede adecuarse como un trasfondo que intentaría albergar los términos de la relación, asegura para cada una de las subjetividades la conservación de su sentido único, particular e incomparable, capacitadas, además, para entrar en el recibimiento de la idea de lo infinito, en relación con el Otro.

\section{Referencias}

Derrida, J. (1989). Escritura y Diferencia. Patricio Peñalver (tr.). Barcelona: Anthropos.

Hoyos Vásquez, G. (1999, may-dic.). La ética fenomenológica y la intersubjetividad. Franciscanum: Revista de las Ciencias del Espíritu, 122-123, vol. 41, 127-145. Bogotá.

Lévinas, E. (2000). Totalidad e Infinito. Ensayo sobre la exterioridad. Daniel E. Guillot (tr.). Salamanca: Sígueme. 
Peñalver, P. (1998, ene-feb). Del tiempo finito al tiempo infinito. En Nogueira, Ángel Dobarro. Emmanuel Lévinas. Un compromiso con la Otredad. Pensamiento ético de la intersubjetividad, 176, 54-59. Barcelona: Antrophos.

Peñalver, P. (2001). Argumento de alteridad. La hipérbole metafísica de Emmanuel Lévinas. Madrid: Caparrós.
Sucasas, A. (1998, ene-feb). La subjetivación. Hipóstasis gozo. En Nogueira, Ángel Dobarro. Emmanuel Lévinas. Un compromiso con la Otredad. Pensamiento ético de la intersubjetividad, 176, 38-43. Barcelona: Antrophos. 